\title{
THE IMPACT OF DIGITIZATION ON THE ECONOMY OF KSA IN THE CONTEXT OF VISION 2030
}

\author{
Wasmi Woishi \\ College of Business \& Administration \\ Department of MIS \\ Al Yamamah University, Riyadh, KSA
}

\begin{abstract}
Today's world is rapidly influenced by data. Globally eight billion devices from smartphones to trains and wind turbines are connected to the internet and this number is expected to grow to one trillion by 2030. Digital transformation or digitization is a key factor of Saudi Arabia's VISION 2030. Digitization is redefining the organization's process and systems digitally. It is reinventing communication, experience and overall efficiency of organizations by artificial intelligence and analytics. The benefits of digitization are witnessed across all sectors whether it's private or public. Human and machines are working hand in hand in refactoring business processes and innovation. Digitization is optimizing value generation and decision-making process to increase business agility. Digitization is provoking the economic sector through more productive, more effective, more competitive product services and solutions delivery. The purpose of the study is to analyze the effects of digitization on the economy of KSA and its contribution toward the VISION 2030. The conclusion was drawn that the impact of digitization on the economy is inevitable and needed to recognize it for, it will greatly contribute towards the VISION 2030. The educational industry could play a vital role in educating and training the young generation so that the young generation can prepare for the opportunities and challenges yet to come.
\end{abstract}

Keywords - Economy of KSA, Digitization, Digital technology, VISION 2030, Digitalization, Global Economy, Middle East Economy.

\section{INTRODUCTION}

The term digitization is the process of converting information into a digital format in which the information is organized into bits. Digitization in terms of money meaning any means of payment that exists purely in electronic form. Digital money is not tangible like a dollar bill or a coin. It is accounted for and transferred using computers. The most successful and widely used form of digital money is the cryptocurrency Bitcoin.
With the passage of time, digitization has become an integral part of enforcing a country's economic activity. According to Pearce-Mosses (2005) "Digitization is the process of transforming analog material into the binary electronic (digital) form especially for storage and use in a computer. In the era of $21^{\text {st }}$-century thousands of zillions of information is created through various means with a blink of an eye. The world is witnessing continual change with the help of digitization. As technology is improving more and more people around the world participate in the digital economy. According to PWC (2012), the mass adoption of digital applications through connected services and devices, known as digitization, is proving to be a powerful means of delivering services, highly disruptive of multiple industries, and wealth and jobs creator. It's no doubt the effect of digitization is noticed in the relationship between customers, workers, and employers. People all around the world are increasingly influenced in using digital money in currency transaction whether it is to buy, sell, transfer or even earning money online. Digital money has successfully dragged its attention immensely throughout the world. It is proven to bring benefit for both governments and corporations as well as individuals. Digital money innovation driving developed market engaged in peer to peer s peer-to-peer (P2P) payments and tap-and-pay at the point of sale (POS). According to Forbes in 2011, digitization added $\$ 193$ billion to world economic output and created 6 million jobs. In the same year in the Middle East and North Africa alone, digitization resulted in an extra $\$ 16.5$ billion in output and nearly 380,000 new jobs. However, as you go deep into digitization you will notice its influence varies among different nations.

The digitization of the Saudi economy development is driven by the ministry of commerce and investment $\&$ their "digital arms" (companies operating in related field) for more than a decade. It has introduced services relating to commercial resister data with the association of Thiqah Business Services which tremendously replaced time consumption in the process extracting information and made it technology-friendly. Saudi 


\section{International Journal of Engineering Applied Sciences and Technology, 2019 \\ Vol. 4, Issue 4, ISSN No. 2455-2143, Pages 312-316 \\ Published Online August 2019 in IJEAST (http://www.ijeast.com)}

Arabia has undergone significant changes in its labor market through digitization. It's expected that half a million jobs will be created through digitization by 2020. According to "Shaping the Future of Work" labor market will be boomed with 226,000 applicants reaching age population of 17.9 million by 2025 .

The growing gap among nations at the top and bottom of the GCI rankings will have significant consequences in the future if not dealt with today. At the cutting edge of the Digital Economy, nations with access to advanced ICT are innovating new business models and prospering as developing nations lag behind and struggle to stay competitive. But the research also makes clear that opportunities remain for nations at all stages of development. Those that make even modest investments to expand broadband use and gain access to Cloud capabilities have the potential to create innovative new business models, products and services. With that in mind, the GCI provides policymakers with intelligence and actionable insights on how best to leverage ICT Infrastructure to help their nations develop innovative approaches to build sustainable economic growth in a hyper-competitive global market. The research will add a valuable benchmark to policymakers of all stages of the digital economy.

The aim of this paper is to analyze the impact of digitization on KSA and how it's going to contribute toward VISION 2030.

\section{LITERATURE REVIEW}

Policymakers, economists, and industry are deeply concerned about the impact of digitization across the world. As digitization is affecting all sectors such as jobs, wages, inequality, health, resource efficiency, and security, society is concerned more than ever before. According to PWC, three key challenges are evident before policymakers to deal with due to the rapid growth of ICT services throughout the world. Initiating standard performance indicator to measure the exposure of ICT among societies is the most significant concern of policymakers. In a rapidly emerging world, policymakers need to revise their policies along with the ICT changes it is witnessing. Another obstacle to tackle for policymakers is to introduce a practical and reliable new technique and procedures to help determine the mass adoption of connected digital technologies and applications is having on societies and economies. These techniques may bring promising benefits to leading governments ambitious and willing to invest in the ICT sector. The third challenge is to implement new techniques to obtain complimentary benefits from them. Policymakers need to assure consumers, businesses and public institutions in working hand in hand to promote established regulations.

\section{A. The scale to measure digitization score}

PWC has identified the measures to calculate any country's digitization in terms of following 6 dimensions
Ubiquity: This term refers to the accessibility to digital services and applications in order to satisfy consumers and enterprises need. It includes
- $\quad$ Fixed broadband penetration
- Mobile phone penetration
- Mobile broadband penetration
- $\quad$ PC population penetration
- $\quad 3 \mathrm{G}$ mobile connection penetration

Affordability: As the name indicates it refers to the pricing in a range that helps digital services available to as many people as possible. It includes
- $\quad$ Fixed-line installation cost
- $\quad$ Fixed cost per minute
- Mobile connection fee
- $\quad$ Mobile prepaid tariff
- $\quad$ Fixed broadband Internet access tariff

Reliability: This term refers to the quality of the available digital services. It includes

- Investment per telephone subscriber (mobile, broadband and fixed)

Speed: This term refers to the accessibility of digital services in real-time. It includes

- International internet bandwidth (bits/second/internet user)

- $\quad \%$ of internet connections above $2 \mathrm{Mbps}$

Usability: The extent to use digital services easily and the capability of boosting the adoption of these services by the local ecosystem. It includes

- Internet retail as a \% of total retail

- $\quad$ E-government web measure index

- $\%$ of individuals using the internet

- Data as a \% of wireless average revenue per user

- $\quad$ IP addresses per 100 inhabitants

- $\quad$ Social network unique visitors per month

- $\quad$ Average SMS usage per customer

Skill: The term refers to the user's ability to blend digital services into their lives and corporations; it includes

- $\quad$ Engineers per 100 inhabitants

- $\%$ of the labor force with more than secondary education

\section{B. Stages of digitization}

There are 4 stages of digitization which can be classified as constrained economies, emerging economies, transitional economies \& advanced economies. These stages have been formed on a scale of 0-100. The score determined which stage is in a certain economy. PWC measured digitization of 150 countries so that it can recognize a countries position in terms of digitization, and it can assist policymakers to give an insight on how to progress.

Constrained economies: Countries digitization score below 25 considered to be in this stage. Such countries struggling with having ease of accessibility and affordability of digital services. People in these countries have limited access to 


\section{International Journal of Engineering Applied Sciences and Technology, 2019 \\ Vol. 4, Issue 4, ISSN No. 2455-2143, Pages 312-316 \\ Published Online August 2019 in IJEAST (http://www.ijeast.com)}

digital services as the service expense is expensive and limited in reach.

Emerging economies: Countries digitization score below 2530 considered to be in this stage. These countries are trying to tackle the affordability issue and progressing notably in providing affordable and widespread access. However, the reliability of the services remained limited.

Transitional economies: This is the $3^{\text {rd }}$ stage of digitization in which countries digitization score in the range of 30 to 40 included. Countries identified the ubiquitous, affordable and reasonably reliable digital services and provided it to the public. However, the difference remains in terms of speed, usability and skill indexes with advanced economies.

Advanced economies: This is the topmost stage of digitization. Countries greater than 40 digitization score are under this category. These economies are strong in providing advanced technology with high usability, speed, and quality digital product and services.

\section{THE IMPACT OF DIGITIZATION GLOBALLY}
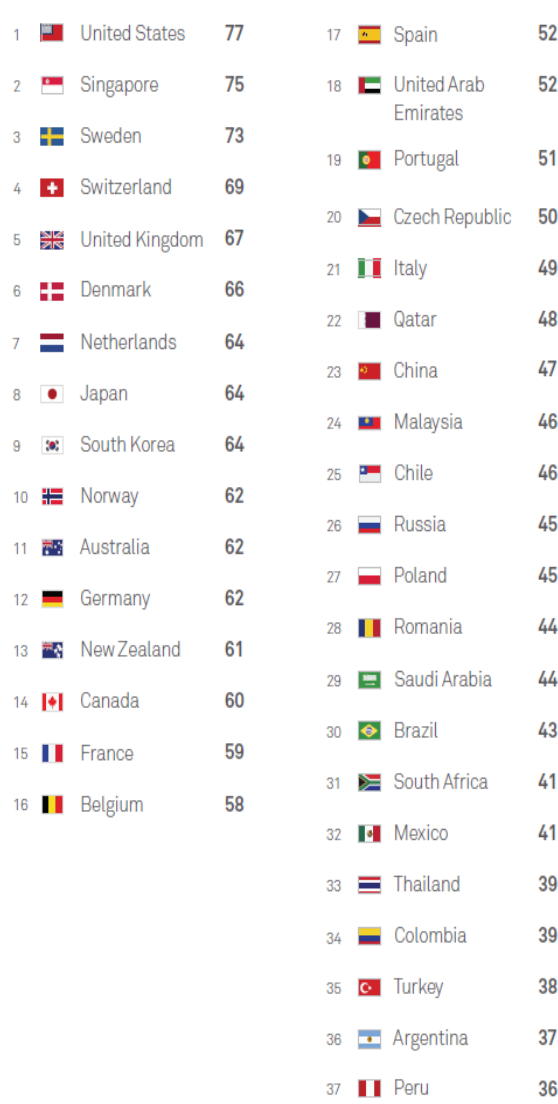

Fig No. 1: Country Rankings [ Source: Global Connectivity index 2017]

50 countries digitization is indicated above who are in different stages of digitization (fig. 1). According to the global connectivity index the US is leading in ICT Infrastructure investment with a score of 77 being in an advanced stage of digitization. After that, Singapore and Sweden are in $2^{\text {nd }}$ and $3^{\text {rd }}$ adopters of ICT infrastructure with a score of 75 and 73 respectively. Moreover, Switzerland, UK, Denmark, Netherlands, Japan, South Korea, Norway are in the top 10 countries who developed their ICT infrastructure. Furthermore, among the Arab countries, Qatar has the highest Digitization score 48. After that, the following countries are China, Malaysia, Chile, Russia, Poland. Furthermore, Romania and Saudi Arabia have the same digitization score 44, Brazil has 43 South Africa and Mexico have 41. After South Africa all the countries are in transitional, emerging and in constrained economies. Looking into some transitional economies such as the Philippines, Indonesia and Vietnam are leading starters' cluster in 2017. South Asian countries such as India, Bangladesh \& Pakistan's digitization score is 32, 26 and 23. India is in a transitional stage and Bangladesh is in an emerging stage and Pakistan is in a constrained economy.

\section{TOP MOVERS COUNTRIES IN DIGITIZATION}

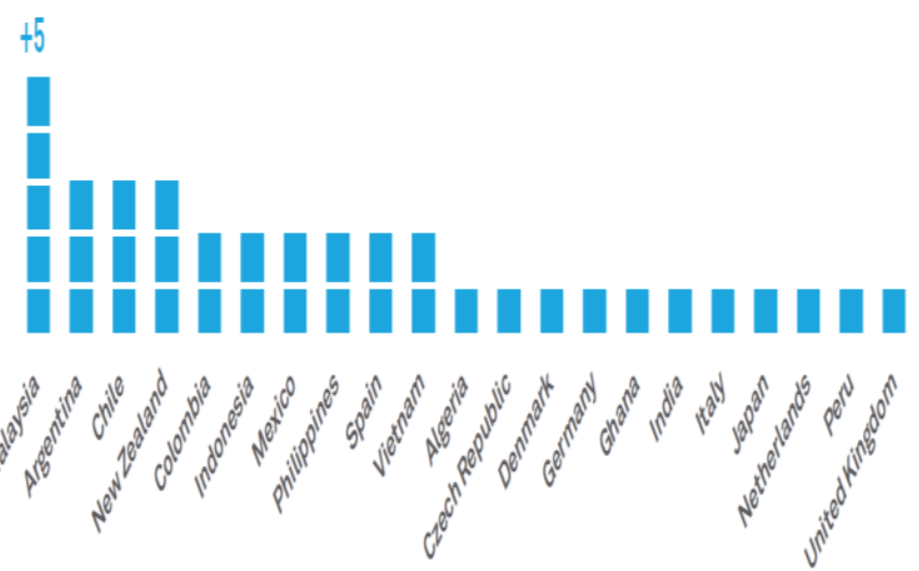

Fig No. 2: Top Moving Countries in digitization [ Source: Global Connectivity index 2017]

According to Global Connectivity Index 2017 overall, 21 nations improved their rank from the GCI 2015 to GCI 2017 (Fig. No. 2). Malaysia made the most impressive progress in ICT infrastructure climbing up five positions. Other nations such as Argentina, Chile, and New Zealand climbed up 3 positions up in ICT sector development. Furthermore, Colombia, Indonesia, Mexico, the Philippines, Spain, and Vietnam all climbed up two positions. And Algeria, Czech Republic, Denmark, Germany, Ghana, India, Italy, Japan, Netherlands, Peru, and the UK all these countries climbed up by 1 position. 


\section{FALLING BEHIND COUNTRIES IN DIGITIZATION}

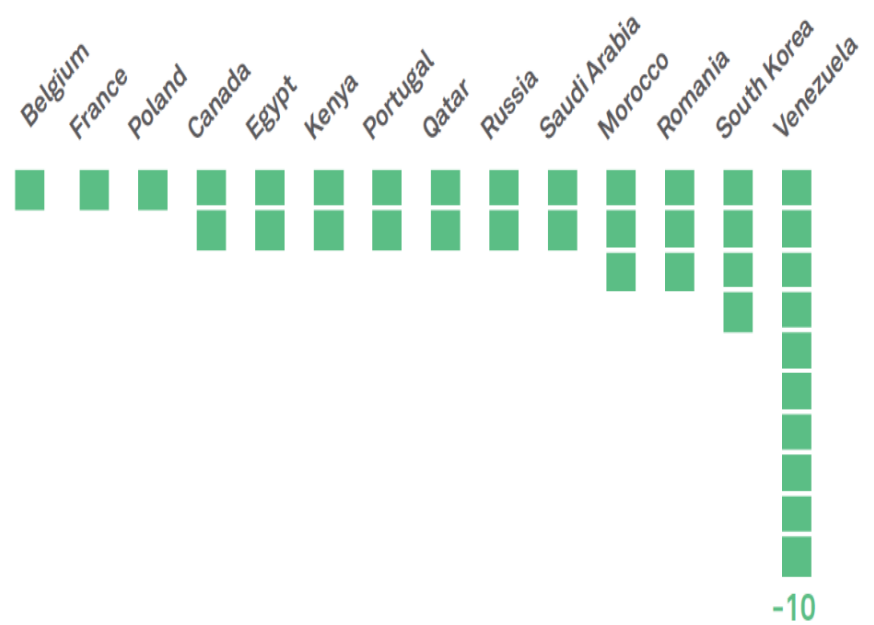

Fig. No. 3: Falling behind countries in digitization [ Source: Global Connectivity index 2017]

According to Global Connectivity Index 2017, some countries are falling behind in developing ICT infrastructure (Fig.No.3). Venezuela stands out as the nation that dropped 10 positions down the GCI ranks over the three-year period, due to that nation's ongoing political and economic crisis. Other nations that saw a significant drop in the GCI were South Korea, dropping four positions, as well as and Morocco and Romania, which each fell by three positions. Saudi Arabia, Russia, Qatar, Portugal, Kenya, Egypt, Canada dropped by 2 positions and Poland, France and Belgium dropped by 1 position.

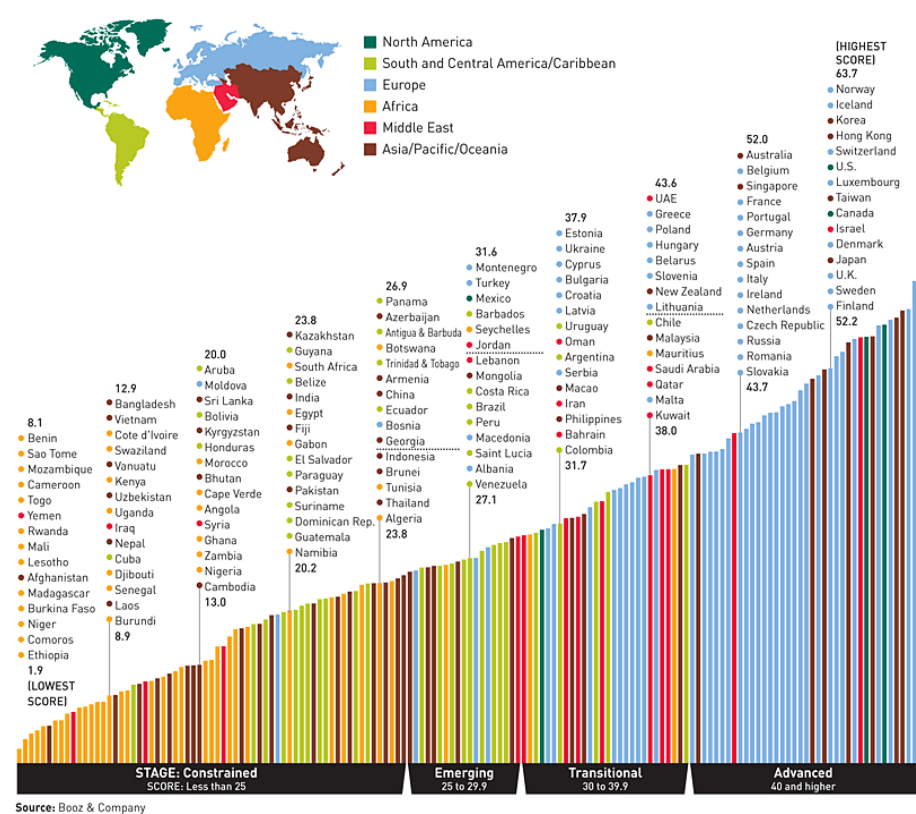

Fig. No. 4: Digitization Score of 150 Countries.
The range of digitization scores shows for 150 countries. Among them, 38 countries are in an advanced stage of ICT infrastructure development. 28 countries are in the transitional stage and 19 are in the emerging stage. However, 65 countries are still in the constrained stage in ICT infrastructure development.

\section{DIGITAL TRANSFORMATION IN SAUDI ARABIA}

According to Dahad. N 2017 Saudi Arabia is the largest spender on ICT in the Middle East, with spending estimated at $\$ 35$ billion in 2015 and expected to surpass $\$ 39$ billion by 2019. The adoption and use of ICT by individuals and enterprises in the public and private sectors have been rising rapidly in recent years. Saudi Arabia's healthcare and tourism industries are also poised to embrace emerging technologies in order to enhance the services they offer. Manufacturing is one obvious beneficiary, where the Internet of things (IoT) will enable manufacturers to leverage a combination of software, sensors, and IP-enabled connectivity to drive innovation around their products and processes. Saudi Arabia expects ICT usage and digitization to accelerate the execution of the programs and plans envisaged in the Vision 2030 blueprint and the NTP, and help drive economic and social development, promote good governance, and enhance national security. Government systems (e.g., customs and payment systems) can provide an open interface that facilitates integration with all private sector players in the supply chain ecosystem. Digitization will also play a central role in achieving the milestones of the NTP. The program identifies a number of digital transformation areas to support the NTP's initiatives, including five common digital platforms, 29 essential digital initiatives for key sectors, and a number of national digital assets that may be developed to support government digital transformation. According to Arab News (2018), the Saudi ministry of justice said $40 \%$ increase has been seen because of the digital transformation program. The ministry has progressed toward implementing NTP 2020. According to MCIT 2019, Saudi Arabia ranked $5^{\text {th }}$ in the use of "Digital Government" in a study conducted by Accenture. According to the report, "high-performing digital governments are: Focusing on their digital strategy, which is deeply embedded in the government agenda and public reforms. Continuing long-term investment in key information and communication technology (ICT) assets and the digitalization of core public services, such as taxation, pensions, and healthcare."

\section{CONCLUSION}

One of the major goals of vision 2030 is to be listed as one of the top 10 countries by 2030 , from its current ranking of $25^{\text {th }}$ in the annual Global Competitive Index. Technology will be a key enabler and driver of the numerous changes envisaged by Vision 2030, with the goal of developing the nation's digital infrastructure and stimulating the related economic sectors, industries, and private sector entities. To achieve these 
outcomes, telecommunications providers will need to provide a highly developed and resilient communications infrastructure, SMEs will need to rapidly embrace ICT solutions and services, and the local IT industry will need to innovate and develop more valuable products and services. The education system will also need to refocus its efforts on nurturing the existing ICT skills base.

\section{REFERENCES}

[1] Arab News (2018). 40\% increase in output through digitalization: Saudi justice ministry.

[2] Dahad. N (2017). Technology is key to Saudi Arabia's National Transformation Program under Vision 2030. A medium

[3] GCI (2017). Harnessing the Power of Connectivity. Huawei white paper.

[4] MCIT (2019). Saudi Arabia Ranks 5th In Digital Government. Ministry of Communication \& Information Technology.

[5] PWC (2012). Maximizing the impact of digitization. White paper.

[6] Sheppard. L. (2018). Digitization will transform the global economy. International Institute for Applied Systems Analysis. Policy Brief No. 20

[7] UNDP Human Development Index, (2010)

[8] Hartley, S. and M. Mackenzie. 2009. "Mobile Broadband Users and Revenues Forecast Pack to 2014." London: Ovum Plc. April 2, Pub ID: OV2270654.

[9] Idowu, P., D. Cornford, and L. Bastin. 2008. "Health Informatics Deployment in Nigeria." Journal of Health Informatics in Developing Countries 2 (1): 15-23.

[10] Digital Europe. 2010. “Digital Europe's Vision 2020: A Transformational Agenda for the Digital Age." White Paper.

[11]CITC (Communications and Information Technology Commission). 2010. Annual Report 2010.

[12] Kamel, S. 2009. "The Evolution of the ICT Sector in Egypt: Partnership4Development." Communications of the IBIMA 10 (2009): 39-49. 